\title{
Crioprotetores na estabilidade do surimi de matrinxã (Brycon amazonicus Spix e Agassiz 1819) sob congelamento
}

Euclides Luis Queiroz de Vasconcelos ${ }^{1}$; Eyner Godinho Andrade ${ }^{2}$; Maria do Perpetuo Socorro $\underline{\text { Rocha }}^{3}$; Illen Soares Taveira ${ }^{1}$; Antônio José Inhamuns ${ }^{4}$; Pedro Roberto de Oloveira ${ }^{4}$; $\underline{\text { Natália }}$ Marques Uchôa ${ }^{5}$; Anita Lima de Souza ${ }^{6}$

${ }^{1}$ Acadêmicos de Engenharia de Pesca, Faculdade de Ciências Agrárias (FCA), Universidade Federal do Amazonas (UFAM)

${ }^{2}$ Engenheiro de Pesca, Doutorando em Ciências Pesqueiras nos Trópicos (UFAM)

${ }^{3}$ Engenheira de Pesca, Doutora em Ciências Pesqueiras nos Trópicos (UFAM)

${ }^{4}$ Engenheiro de Pesca, Professor Doutor da FCA-UFAM

${ }^{5}$ Engenheira de Pesca pela UFAM

${ }^{6}$ Bióloga, Mestre em Biotecnologia (UFAM)

*Autor para correspondência - e-mail: euclides_luis15@hotmail.com

RESUMO. O surimi é carne de pescado, submetida a lavagens sucessivas, onde se eliminam gordura, sangue, substâncias odoríferas e proteínas solúveis em água, resultando em pasta branca, sem odor e sabor característicos de peixe, permitindo melhor aproveitamento do pescado e dos resíduos gerados pelo processamento. Entretanto, sua estabilidade durante o congelamento depende do uso de crioprotetores, que conferem menor perda de umidade durante a estocagem e no descongelamento. Testaram-se três formulações com misturas de três compostos crioprotetores para avaliar o que proporciona maior estabilidade ao surimi de matrinxã. A carne mecanicamente separada (CMS) foi submetida a três ciclos de lavagem em água gelada $\left(0\right.$ a $\left.5^{\circ} \mathrm{C}\right)$ e de $\mathrm{pH}$ ajustado para 7,0 (0,5\% de bicarbonato de sódio), a fim de retirar as proteínas sarcoplasmáticas, lipídios e pigmentos heme. Para retirada do excesso de água, a CMS lavada foi submetida à pressão em prensa hidráulica. A capacidade de retenção de água (CRA) foi maior para o tratamento 3 (6\% de sacarose, $6 \%$ de sorbitol e $0,5 \%$ de tripolifosfato), com 90,04\%, indicando maior estabilidade do surimi de matrinxã sob congelamento. A SDS-PAGE revelou que a miosina de cadeia pesada foi muito mais suscetível à hidrólise do que a actina, sendo mais propensa à degradação proteolítica do que outras proteínas como actina, troponina e tropomiosina.

Palavras-chave: Tecnologia de alimentos, pescado de água doce, gel de surimi.

\section{Cryoprotectants in the stability of "surimi" of matrinxã (Brycon amazonicus Spix e Agassiz 1819) under freezing}

\begin{abstract}
Surimi is a fish meat, subjected to successive washes, where they eliminate fat, blood, odoriferous substances and water-soluble proteins, resulting in a white paste, no odor and flavor of fish, allowing better utilization of fish and waste generated from processing. However, their stability during freezing depends on the use of cryoprotectants, which lead to lower moisture loss during storage and thawing. Were tested three formulations with mixtures of three compounds cryoprotectants to assess which provides greater stability surimi matrinxã. The meat mechanically separate was subjected to three cycles of washing with cold water $\left(0\right.$ to $\left.5^{\circ} \mathrm{C}\right)$ and adjusted to $\mathrm{pH} 7.0(0.5 \%$ sodium bicarbonate) in order to remove the sarcoplasmic proteins, lipids and pigments heme. To remove excess water, washed CMS was subjected to pressure in a hydraulic press. The water holding capacity (WHC) was higher for
\end{abstract}


Treatment 3 (6\% sucrose, $6 \%$ sorbitol and $0.5 \%$ of tripolyphosphate) with $90.04 \%$, indicating greater stability in frozen surimi matrinxã. SDS-PAGE revealed that the heavy chain myosin was much more susceptible to hydrolysis than actin, being more prone to proteolytic degradation of other proteins such as actin, tropomyosin and troponin.

Key-words: Food technology, manufactured product, surimi gel.

\section{Introdução}

A indústria de produtos pesqueiros vem enfrentando muitos problemas, e para solucionálos, o setor busca o desenvolvimento de novos produtos e novos mercados, bem como a expansão dos setores produtivos. O surimi constitui uma das alternativas para diversificar os produtos de pescado para a indústria. A qualidade e o preço do surimi são medidos por meio da sua capacidade em formar géis fortes e com grande elasticidade (An et al., 1994).

O Codex Alimentarius (2009) define o surimi como sendo um produto de proteínas de peixes que passou pelas etapas de descabeçamento, evisceração e limpeza do pescado fresco, procedendo sua separação mecânica do músculo comestível, da pele e dos ossos, em seguida sendo lavado, refinado, desidratado e misturado a crioprotetores e congelado.

Buscando elucidar os mecanismos da desnaturação protéica em espécies de peixes tropicais da Amazônia, este estudo teve a finalidade de avaliar os efeitos da adição de crioprotetores no surimi de matrinxã durante sua estocagem sob congelamento.

\section{Material e métodos}

\section{Material}

O surimi foi obtido a partir de matrinxã $(B$. amazonicus Spix e Agassiz 1819) pesando cerca de $1 \mathrm{~kg}$, totalizando 20 peixes, provenientes de viveiros de piscicultura próximos à cidade de Manaus-AM. Os peixes foram abatidos por hipotermia, em seguida foram acondicionados em caixa isotérmica com gelo na proporção 1:1 (gelo:peixe) e transportados até a Coordenação de Pesquisas em Tecnologia de Alimentos, no Instituto de Pesquisas da Amazônia, onde foi realizada a separação mecânica do músculo do pescado, das peles e espinhas, obtendo assim a carne mecanicamente separada.

\section{Metodologia}

A carne mecanicamente separada (CMS) foi submetida a três ciclos de lavagem em água gelada $\left(0\right.$ a $\left.5{ }^{\circ} \mathrm{C}\right)$ e de $\mathrm{pH}$ ajustado para $7,0(0,5 \%$ de bicarbonato de sódio). Para retirar o excesso de água, a CMS lavada foi submetida à pressão em sacos de fibras de algodão em prensa hidráulica.

Em seguida foram acrescentados à CMS os crioprotetores comumente utilizados na indústria do surimi (Yongsawatdigul et al., 2000) aplicou-se os tratamentos: tr0 - (surimi sem adição de crioprotetores); tr 1 - (surimi com $2 \%$ de sacarose, $2 \%$ de sorbitol e $0,1 \%$ de tripolifosfato); tr2 (surimi com $4 \%$ de sacarose, $4 \%$ de sorbitol e 0,3 $\%$ de tripolifosfato); tr3 - (surimi com $6 \%$ de sacarose, $6 \%$ de sorbitol e $0,5 \%$ de tripolifosfato).

Para avaliar a desnaturação provocada pelo processo de separação mecânica e pelas condições de estocagem, foram retiradas amostras de surimi com crioprotetores, e sem crioprotetores a cada 30 dias durante 120 dias, utilizando os seguintes testes:

- Análise de capacidade de retenção de água: utilizando a técnica de Roussel \& Cheftel (1990) modificada por Souza (2001).

- Análise de SDS-PAGE, método proposto por Huidobro, et al. (1998) para avaliar a eficiência dos crioprotetores na prevenção da desnaturação protéica. Os dados foram submetidos à análise de variância e ao teste de comparação de médias de Tukey (HSD) a 5\% de significância.

\section{Resultados e discussão}

A capacidade de retenção de água (CRA) observada na figura 1 é uma propriedade de importância fundamental em termos de qualidade tanto na carne destinada ao consumo direto, como para a carne destinada à industrialização. Pode ser definida como a capacidade da carne de reter sua umidade ou água durante a aplicação de forças 
externas, como corte, aquecimento, trituração e prensagem (Pearce et al., 2011).

$\mathrm{O}$ aumento gradual no percentual de crioprotetores propiciou maiores percentuais na capacidade de retenção de água, o tratamento 3 (6\% de sacarose, $6 \%$ de sorbitol e $0,5 \%$ de tripolifosfato) foi o que melhor reteve a umidade, com diferença dos demais tratamentos $(\mathrm{p}<0,05)$.

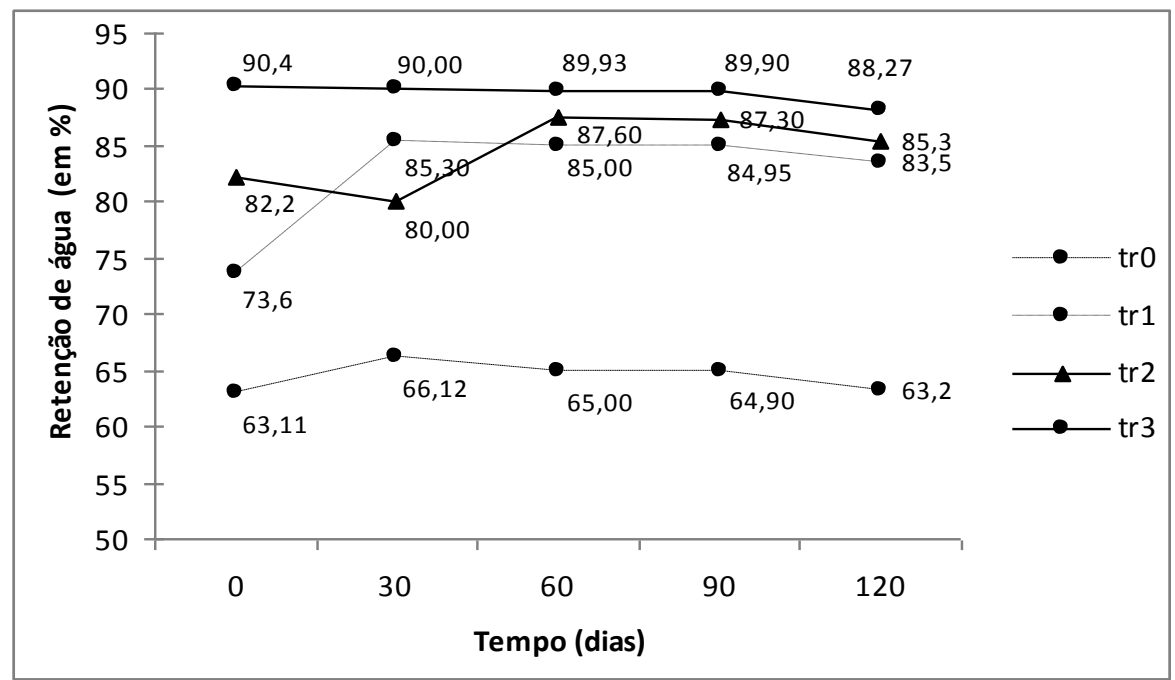

Figura 1. Capacidade de Retenção de Água (CRA) do surimi de matrinxã. Legenda: tr0 - surimi sem adição de crioprotetores; $\operatorname{tr} 1$ - (2\% de sacarose, $2 \%$ de sorbitol e $0,1 \%$ de tripolifosfato); tr 2 - (4\% de sacarose, $4 \%$ de sorbitol e $0,3 \%$ de tripolifosfato); tr 3 - (6\% de sacarose, $6 \%$ de sorbitol e $0,5 \%$ de tripolifosfato).

Os padrões de SDS-PAGE (Figura 2), Morrissey (1997) que encontraram a miosina de revelaram que miosina de cadeia pesada foi muito cadeia pesada mais propensa à degradação mais suscetível à hidrólise do que a actina. Este proteolítica do que as outras proteínas, como por resultado está de acordo com Benjakul \& exemplo: actina, troponina e tropomiosina.

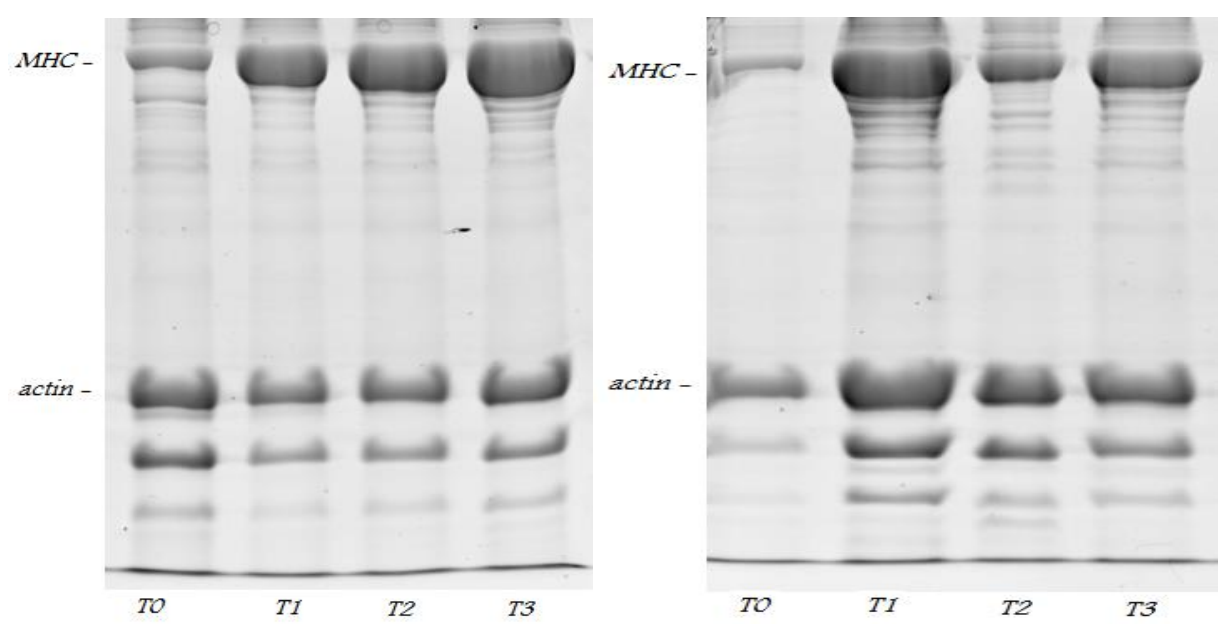

Figura 2. Padrão de SDS-PAGE de proteínas do surimi sem crioprotetores e surimi de matrinxã com crioprotetores durante o início do experimento e após 120 dias de armazenamento congelado. Legenda: tr0 - surimi sem adição de crioprotetores; tr 1 - (2\% de sacarose, $2 \%$ de sorbitol e $0,1 \%$ de tripolifosfato); tr $2-(4 \%$ de sacarose, $4 \%$ de sorbitol e $0,3 \%$ de tripolifosfato); $\operatorname{tr} 3-(6 \%$ de sacarose, $6 \%$ de sorbitol e $0,5 \%$ de tripolifosfato). MHC - miosina de cadeia pesada; actin - actina 
A diferença observada nos 120 dias de estocagem, no tratamento 0 (surimi sem adição de crioprotetores) pode ser atribuído as diferenças de estabilidade das proteínas diante da desnaturação, em função da composição de resíduos de aminoácidos, que estão presentes nos diferentes tipos de músculos que compõe o pescado, fato que vem sido descrito por vários autores como Ataman et al. (2006). Esses autores se referem ainda que a migração iônica pode ocorrer mais rapidamente e apresentar bandas mais claras de proteínas. Outros fatores descritos na literatura que podem influenciar nos padrões de banda, segundo Rehbein (1990) são: o frescor do pescado e as condições de armazenagem.

\section{Conclusão}

O tratamento 3 (6\% de sacarose, $6 \%$ de sorbitol e $0,5 \%$ de tripolifosfato) foi o que obteve melhores resultados na estabilidade do surimi de matrinxã sob congelamento quanto a capacidade de retenção de água, permitindo afirmar que minimizou a desnaturação protéica durante a estocagem. E padrões de SDS-PAGE, revelaram que miosina de cadeia pesada foi mais propensa à degradação proteolítica do que outras proteínas.

\section{Referências bibliográficas}

An, H., Weerasinghe, V., Seymour, T. \& Mprrisey, M. T. 1994. Cathepsin degradation of Pacific whiting surimi proteins. Journal of Food Science, 59, 1013-1017.

Ataman, C., Çelik, U. \& Rehbein, H. 2006. Identification of some Aegean fish species by native isoelectric focussing. European Food Research and Technology, 222, 99-104.

Benjakul, S. \& Morrissey, M. T. 1997. Protein hydrolysates from Pacific whiting solid wastes. Journal of Agricultural and Food Chemistry, 45, 3423-3430.

Fao / Who. (2009). Code of Practice for fish and fishery products. Codex Alimentarius Commission, First Edition. Rome, p.8.
Huidobro, A.; Montero, P.; Bordeiras, A. J. (1998). Emulsifing properties of na ultrofiltered protein from minced fish wash water. Food Chemistry., 61, 339-343.

Pearce, K. L., Rosenvold, K., Andersen, H. J. \& Hopkins, D. L. 2011. Water distribution and mobility in meat during the conversion of muscle to meat and ageing and the impacts on fresh meat quality attributes - A review. Meat Science, 89, 111-124.

Rehbein, H. 1990. Electrophoretic techniques for species identification of fishery products. Zeitschrift für Lebensmittel-Untersuchung und Forschung, 191, 1-10.

Roussel, H. \& Cheftel, J. C. 1990. Mechanisms of gelation of sardine proteins: influence of thermal processing and of various additives on the texture and protein solubility of kamaboko gels. International Journal of Food Science \& Technology, 25, 260-280.

Souza, F. C. A. 2001. Influência da desnaturação protéica sobre a qualidade do "minced fish" de peixes amazônicos. Ciências de Alimentos. Universidade do Amazonas, Manaus. 48p.

Yongsawatdigul, J., Park, J. W., Virulhakul, P. \& Viratchakul, S. 2000. Proteolytic degradation of tropical tilapia surimi. Journal of Food Science, 65, 129-133.

Recebido em Janeiro 20, 2016

Aceito em Fevereiro 18, 2016

License information: This is an open-access article distributed under the terms of the Creative Commons Attribution License, which permits unrestricted use, distribution, and reproduction in any medium, provided the original work is properly cited 